\title{
Effect of clarithromycin on rhinovirus-16 infection in A549 cells
}

\author{
Y.J. Jang, H-J. Kwon and B-J. Lee
}

\begin{abstract}
Clarithromycin (CM) has been found to inhibit the production of the intercellular adhesion molecule (ICAM)-1 and the secretion of interleukin (IL)-6 and IL-8, which may have beneficial effects on the pathophysiological changes related to rhinovirus (RV) infection. The effect of CM on RV infection in A549 cells was therefore investigated.

Cells were pre-treated with 1,10 or $100 \mu \mathrm{M} C M$, either starting 3 days before infection and continuing thereafter, or by addition at the time of infection. RV titre, as measured by culture on Medical Research Council 5 cells, was reduced by $\mathrm{CM}$, with the degree of reduction being greater when CM was added 3 days before infection than when it was added at the time of infection.

CM treatment inhibited the RV-induced increase in ICAM-1 mRNA and protein, as well as the RVinduced secretion of IL-1 $\beta$, IL-6, and IL-8. These effects were greater in cells treated with $10 \mu \mathrm{M}$ than in those treated with $100 \mu \mathrm{M} \mathrm{CM}$, and the maximum effect was observed 3 days after viral infection. In contrast, secretion of IL-8 was not inhibited significantly when CM was added at the time of viral infection.

The findings of this study suggest that, in A549 cells, clarithromycin inhibits the induction of intercellular adhesion molecule-1 expression, cytokine elaboration, and viral infection.
\end{abstract}

KEYWORDS: Airway epithelial cells, cytokine, macrolides, rhinovirus

$\mathbf{R}$ hinovirus (RV) infections are the most common acute infectious illnesses in humans, accounting for $\sim 5-20 \%$ of acute illnesses [1], including 50-60\% of common colds. RV infections are also important predispositions for other common health problems, including asthma attacks, sinusitis, and otitis media [2]. RV enters the cytoplasm of airway epithelial cells after binding either to its cell surface receptor, intercellular adhesion molecule (ICAM)-1, or to a low-density lipoprotein receptor [3]. Approximately $90 \%$ of $>100$ different RV serotypes bind to ICAM-1 [4], and RV infection upregulates ICAM-1 expression on airway epithelial cells, thus facilitating further viral attachment and entry [5, 6]. RV infection also induces the hypersecretion of mucus [7], as well as the increased expression and secretion of various cytokines, including interleukin (IL)-1 $\beta$, IL-6, IL8 , IL-9, IL-11, and tumour necrosis factor- $\alpha$ [6-8]. The actions of these cytokines, either individually or in combination, are likely to underlie the clinical manifestation of RV infec-

tion [9].

Low-dose, long-term macrolide treatment has been shown to be effective in managing chronic airway diseases, such as diffuse panbronchiolitis and chronic sinusitis [10-12]. These effects are thought to be due to the anti-inflammatory properties of macrolide antibiotics rather than to their antibacterial properties. For example, macrolide antibiotics have been found to inhibit the production of ICAM-1, which is crucial in the accumulation of immune effector cells at sites of local inflammation [13]. Macrolide antibiotics also inhibit the production of IL- 6 and IL- 8 by respiratory epithelial cells [14, 15], and they reduce the activation and chemotaxis of neutrophils [16]. These anti-inflammatory properties of macrolide antibiotics may modulate the pathophysiological changes related to RV infection. Although one macrolide antibiotic, erythromycin, has been reported to inhibit RV infection and reduce $R V$-induced cytokine response [17], there have been no studies on the in vitro effects of clarithromycin (CM), another broad-spectrum, 14-membered-ring macrolide, on RV infection. The effect of CM on RV infection in A549 cells was, therefore, tested.

\section{MATERIALS AND METHODS Clarithromycin}

CM, provided by Hanmi Pharm Co., Ltd (Seoul, Korea) as a preservative-free pure powder, was dissolved in dimethyl sulphoxide (DMSO) and diluted with PBS. To determine the dose response of $\mathrm{CM}$, concentrations of 1,10 and $100 \mu \mathrm{M}$ were

\section{AFFILIATIONS}

Dept of Otolaryngology, Asan Medical Center, University of Ulsan College of Medicine, Seoul, Korea.

CORRESPONDENCE

Y.J. Jang

Dept of Otolaryngology

Asan Medical Center

University of Ulsan College of

Medicine

388-1 Pungnap-2dong

Songpa-gu

Seoul

138-736

South Korea

Fax: 8224892773

E-mail: jangyj@amc.seoul.kr

Received:

January 232005

Accepted after revision:

September 072005
European Respiratory Journal Print ISSN 0903-1936

Online ISSN 1399-3003 
used. To determine the time course effect of $\mathrm{CM}$ and the effect of pre-treatment before RV infection, a concentration of $10 \mu \mathrm{M}$ was chosen, as this is the average serum concentration in clinical use, as well as being most effective in reducing viral titre and inhibiting cytokine secretion in the current study.

\section{Cell culture, rhinovirus infection and clarithromycin treatment}

RV-16 was obtained from the American Type Culture Collection (ATCC, Manassas, VA, USA) and diluted with Dulbecco's modified Eagles medium (DMEM)/F-12K. A549 alveolar epithelial type II-like cells were obtained from ATCC and were grown to confluence in 100-mm Petri dishes in DMEM, supplemented with: nonessential amino acids, Lglutamine, penicillin, streptomycin, and 10\% foetal bovine serum (FBS; Hyclone laboratory, Logan, UT, USA).

For RV infection, A549 cells were plated at $2 \times 10^{5}$ cells per well in 12 -well plates in $10 \% \mathrm{DMEM} / \mathrm{F}-12 \mathrm{~K}$. In the control group, cells were cultured for 10 days in medium containing $0.1 \mu \mathrm{L}$ DMSO, the vehicle for CM. In the RV infection group (RV), culture medium was aspirated on day 4, and the cells were infected with RV-16 stock at a multiplicity of infection of 1 . After adsorption at $37^{\circ} \mathrm{C}$ for $120 \mathrm{~min}$, the viral solution was removed, the cells rinsed with PBS and incubated at $33^{\circ} \mathrm{C}$. In the RV plus $C M$ group $(R V+C M)$, cells were treated with $10 \mu \mathrm{M} C \mathrm{C}$ for 3 days before $\mathrm{RV}$ infection and cultured in medium containing $10 \mu \mathrm{M} \mathrm{CM}$. In the CM-only group (CM), cells were treated with $10 \mu \mathrm{M}$ CM for 10 days without RV infection. In each culture, the supernatant was removed $24 \mathrm{~h}$ after viral adsorption and every day thereafter and clarified by low-speed centrifugation, before being stored at $-70^{\circ} \mathrm{C}$ for viral titration and cytokine measurement.

To determine any difference between pre-treatment with CM for 3 days before RV infection and treatment at the time of viral infection, another set of experiments was conducted without pre-treatment with CM. In this experiment, the supernatant of the control, RV and CM groups was removed after $24 \mathrm{~h}$, and for subsequent days up to 3 days. In the $\mathrm{RV}+\mathrm{CM}$ group, $10 \mu \mathrm{M}$ $\mathrm{CM}$ was treated from the time of viral infection for $120 \mathrm{~min}$, the cells were rinsed with PBS and were incubated at $33^{\circ} \mathrm{C}$ for 3 more days in the media containing CM. Viral titre and cytokine level from the supernatant were compared with the group in which CM was treated from 3 days before infection. For RTPCR analysis of ICAM-1 mRNA and flow cytometric measurement of ICAM-1 expression, the cells were washed with PBS and harvested using $0.25 \%$ trypsin-EDTA $\left(100 \mu \mathrm{L} \cdot\right.$ well $\left.^{-1}\right)$.

\section{Measurement of viral titre}

Medical Research Council (MRC)-5 human lung fibroblasts obtained from the ATCC and cultured at $3 \times 10^{5}$ cells per well in 96-well microplates (Falcon Lab ware, Oxnard, CA, USA) in minimum essential medium (Gibco, Grand Island, NY, USA) containing $2 \mathrm{mM}$ L-glutamine, $20 \mathrm{mM}$ hygroethyl piperazine ethane sulphonic acid, $100 \mathrm{U} \cdot \mathrm{mL}^{-1}$ penicillin, $100 \mu \mathrm{L} \cdot \mathrm{mL}^{-1}$ streptomycin, $0.25 \mu \mathrm{L} \cdot \mathrm{mL}^{-1}$ fungizone and $10 \%$ FBS. On the day of the experiment, $125 \mu \mathrm{L}$ medium was removed from each well, $25 \mu \mathrm{L}$ of serial 10 -fold dilutions of each specimen was added and the plates were incubated at $33^{\circ} \mathrm{C}$ for 7 days. Viral cytopathic effects were examined using an inverted microscope. The amount of specimen required to infect $50 \%$ of MRC- 5 cells
(50\% tissue culture infection dose (TCID50)) was determined, and the viral titre was expressed as TCID $50 \mathrm{U} \cdot \mathrm{mL}^{-1}$.

\section{Measurement of intercellular adhesion molecule-1 mRNA and surface protein expression}

ICAM-1 mRNA was measured by RT-PCR. Total RNA was isolated by TRIzol ${ }$ reagent (Invitrogen, Carlsbad, CA, USA) and reverse transcribed to CDNA; ICAM-1-specific mRNA was assayed using the primers $5^{\prime}$-CACAGTCACCTATGGCAACG3' (sense) and 5'-TTCTTGATCTTCCGCTGGC-3' (antisense). Each PCR mixture contained $2 \mu \mathrm{L}$ of $10 \times \mathrm{PCR}$ buffer (GeneCraft, Lüdinghausen, Germany), $1 \mu \mathrm{L}$ of $2.5 \mathrm{mM}$ deoxynucleotide triphosphates (BioGrand, Seoul, Korea), $0.2 \mu \mathrm{L}$ of Taq polymerase (Genecraft), 10 pmol of each primer and 13.3 $\mu \mathrm{L}$ of double-distilled $\mathrm{H}_{2} \mathrm{O}$ in a final volume of $20 \mu \mathrm{L}$. Amplification was performed with a Perkin-Elmer 9600 thermal cycler (Perkin-Elmer, Wellesley, MA, USA), using a protocol consisting of 35 cycles of denaturation for $30 \mathrm{~s}$ at $94^{\circ} \mathrm{C}$, annealing for $30 \mathrm{~s}$ at $55^{\circ} \mathrm{C}$ and an extension for $30 \mathrm{~s}$ at $72^{\circ} \mathrm{C}$, followed by a final extension for $10 \mathrm{~min}$ at $72^{\circ} \mathrm{C}$. Primers for human $\beta$-actin were used as a loading control.

Surface expression of ICAM-1 was measured by flow cytometry. A549 cells harvested, as described above, were incubated with fluorescein isothiocyanate-conjugated mouse antihuman ICAM-1 antibody (Serotec, Oxford, UK), or isotype-specific control antibody (mouse immunoglobulin G1-fluorescein isothiocyanate; Serotec), for $30 \mathrm{~min}$ at $40^{\circ} \mathrm{C}$. After extensive washing in PBS, each cell preparation was fixed in $200 \mu \mathrm{L} 1 \%$ paraformaldehyde/PBS, and fluorescence was analysed by single colour flow cytometry (FACSCalibur; Becton Dickinson, Franklin Lakes, NJ, USA). The mean fluorescence intensity was normalised relative to noninfected control values, after subtraction of background staining.

\section{Quantification of interleukin-1 $\beta,-6$ and -8}

Immunoreactive IL-1 $\beta$, IL-6 and IL- 8 were quantitated using dual antibody ELISA kits (Biosource, Nivelles, Belgium) according to the manufacturer's protocol. The sensitivity limit of each kit was $10 \mathrm{pg} \cdot \mathrm{mL}^{-1}$. Data were expressed in $\mathrm{pg} \cdot \mathrm{mL}^{-1}$ and were derived by extrapolation from a standard curve generated in parallel with each experiment.

\section{Statistical analysis}

All statistical testing was carried out with a nonparametric signed rank test. All data are reported as the mean \pm SD of at least seven replicate experiments. A value of $\mathrm{p}<0.05$ was considered to be statistically significant.

\section{RESULTS}

\section{Viral titres}

When the supernatants in MRC-5 cells were cultured, it was found that the mean viral titre in the supernatant of the RV group was $10^{3.85} \mathrm{TCID} 50 \mathrm{U} \cdot \mathrm{mL}^{-1}$. In the $\mathrm{RV}+\mathrm{CM}$ group, the titre was $10^{2.15}$ TCID50 $\mathrm{U} \cdot \mathrm{mL}^{-1}$ when $\mathrm{CM}$ was added 3 days before infection, but slightly higher $\left(10^{2.85} \mathrm{TCID} 50 \mathrm{U} \cdot \mathrm{mL}^{-1}\right)$ when $\mathrm{CM}$ treatment was started at the time of viral infection $(p<0.05)$ (fig. 1). This finding indicates that $\mathrm{CM}$ inhibition of viral replication was more effective in cells pre-treated with $\mathrm{CM}$ than when CM was added at the same time as RV. 


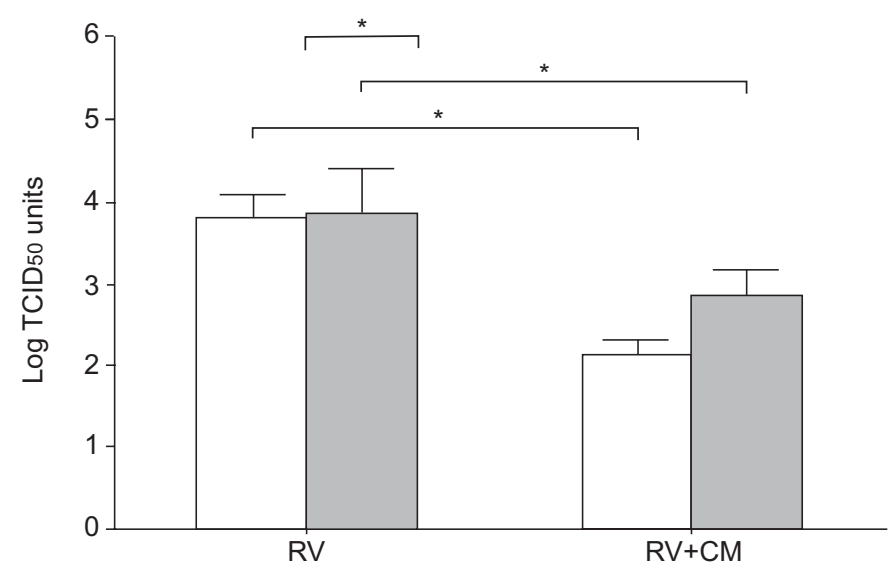

FIGURE 1. Viral titres in supernatants of A549 cells after rhinovirus (RV) infection and after RV infection plus clarithromycin ( $\mathrm{RV}+\mathrm{CM}$ ) pre-treatment. Clarithromycin treatment $(\mathrm{RV}+\mathrm{CM})$ inhibited the $\mathrm{RV}$-induced increase in viral titre. However, cells pre-treated with $\mathrm{CM}$ for 3 days prior to infection had a significantly lower titre than cells to which $\mathrm{CM}$ was added at the time of viral infection. Each bar represents the mean \pm SD of seven samples. $\square$ : pre-treatment; $\square$ : no pre-treatment. TCID50: 50\% tissue culture infection dose. ${ }^{*}: p<0.05$.

When the dose response of pre-treatment was investigated with three $\mathrm{CM}$ concentrations, 1,10 and $100 \mu \mathrm{M}$, for the first 3 days after RV infection, it was found that on the first day the mean viral titre of the $\mathrm{RV}$ and $\mathrm{RV}+\mathrm{CM}(1 \mu \mathrm{M})$ groups was $10^{2.5}$ TCID50 U. $\mathrm{mL}^{-1}$, but was somewhat lower $\left(10^{1.5}\right.$ TCID50 $\mathrm{U} \cdot \mathrm{mL}^{-1}$ ) in cells pre-treated with 10 and $100 \mu \mathrm{M} \mathrm{CM}$ (fig. 2a). On day 2, the titre of the RV group was $10^{2.75}$ TCID50 U.mL ${ }^{-1}$, whereas the titre of cells pre-treated with the three concentrations of $\mathrm{CM}$ was $10^{1.75} \mathrm{TCID} 50 \mathrm{U} \cdot \mathrm{mL}^{-1}$ (fig. 2b). On day 3, the mean viral titre in the RV group was $10^{4.25}$ TCID50 U. $\mathrm{mL}^{-1}$, but the titre in the cells treated with 1 or $10 \mu \mathrm{M} \mathrm{CM}$ was $10^{1.5}$ TCID50 U.mL $\mathrm{mL}^{-1}$ and in cells treated with $100 \mu \mathrm{M}$ it was $10^{2.5}$ TCID50 U. $\mathrm{mL}^{-1}$ (fig. $2 \mathrm{c}$ ), indicating that the lower concentrations of $\mathrm{CM}$ were more effective in reducing RV titre.

When the time course of viral titre was investigated for cells treated with $\mathrm{CM}$ was treated from 3 days before viral infection and treatment continued thereafter, it was found that in the absence of CM the mean titre peaked at $10^{4.75} \mathrm{TCID} 50 \mathrm{U} \cdot \mathrm{mL}^{-1}$ on day 3 after viral infection and then declined to $10^{3.75}$ TCID50 $\mathrm{U} \cdot \mathrm{mL}^{-1}$ on days 5 and 6 . In the $\mathrm{RV}+\mathrm{CM}$ group, the mean viral titre was $\sim 10^{1.5} \mathrm{TCID} 50 \mathrm{U} \cdot \mathrm{mL}^{-1}$ on days 1,2 and 3 and peaked at $10^{3.5}$ TCID50 $\mathrm{U} \cdot \mathrm{mL}^{-1}$ on day 4 , declining to $10^{2.75}$ on days 5 and 6 (fig. 3).

\section{Expression of intercellular adhesion molecule-1}

Using RT-PCR, it was found that RV infection increased ICAM-1 mRNA expression, but this was reduced by CM treatment (fig. 4). However, CM alone had no effect on ICAM-1 mRNA levels in the absence of RV infection (fig. 4). It was observed, using flow cytometry, that the mean fluorescence intensity of control A549 cells was 8.1, which was increased to 9.6 in the $\mathrm{CM}$ group. RV infection increased surface expression of ICAM-1 to 12.4 , which was reduced by CM to 9.2 in the $\mathrm{RV}+\mathrm{CM}$ group. The differences between the control and RV groups, and between the RV and the $\mathrm{RV}+\mathrm{CM}$ groups, were significant (fig. 5).
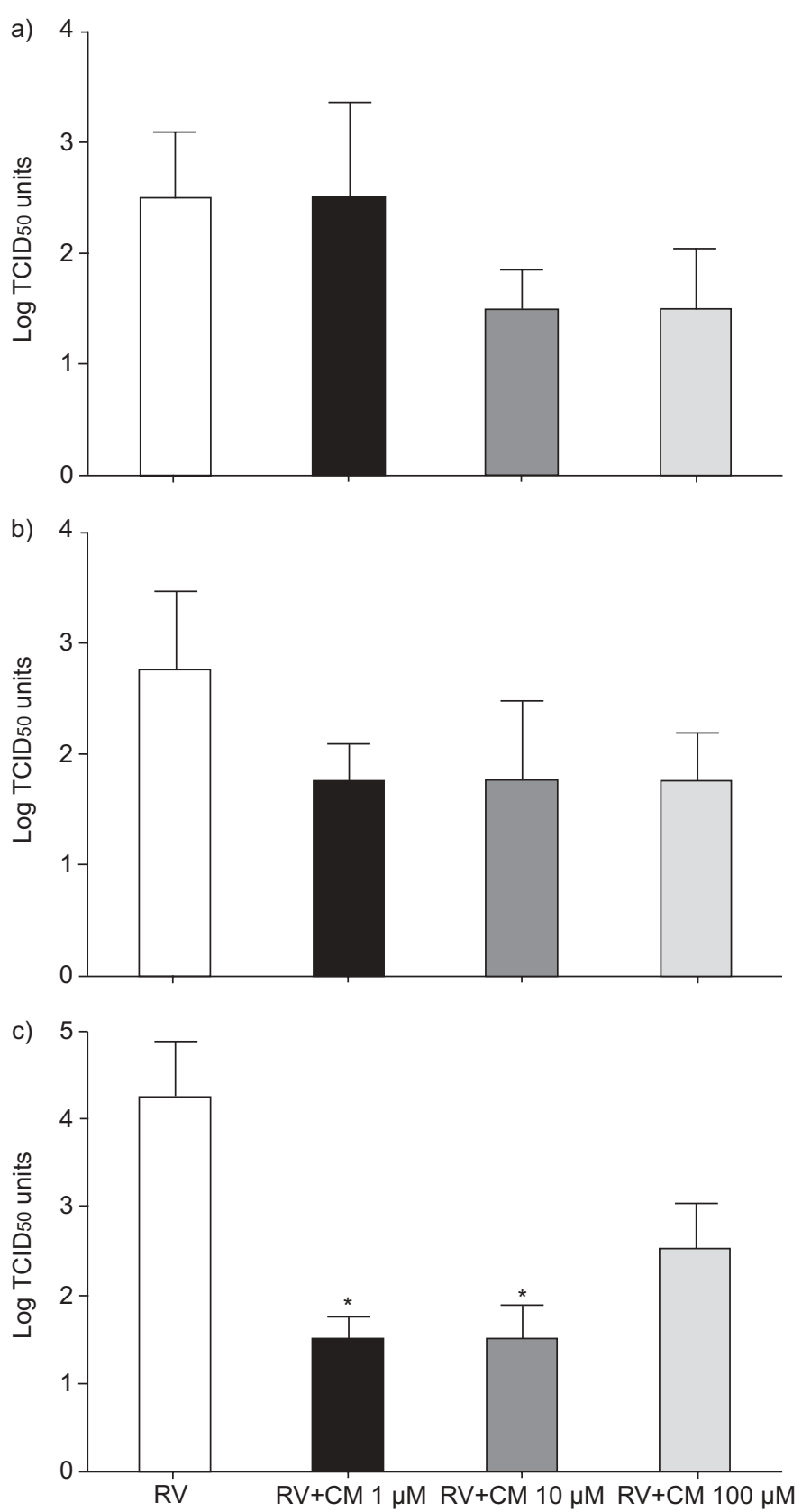

FIGURE 2. The effect of pre-treatment with 1,10 or $100 \mu \mathrm{M}$ clarithromycin (CM) on a) day 1, b) day 2 and c) day 3 after rhinovirus (RV) infection. Each bar represents the mean \pm SD of seven samples. TCID50: $50 \%$ tissue culture infection dose. *: $p<0.05$.

\section{Quantity of cytokines}

When the level of RV-induced cytokine secretion was measured, it was found that on day 3 the mean concentration of IL-1 $\beta$ in the control group was $35.8 \mathrm{pg} \cdot \mathrm{mL}^{-1}$, which was increased to $69 \mathrm{pg} \cdot \mathrm{mL}^{-1}$ in the $\mathrm{RV}$ group. In cells pre-treated with 1 and $10 \mu \mathrm{M} \mathrm{CM}$ and then infected, the IL-1 $\beta$ level was significantly reduced to $35.8 \mathrm{pg} \cdot \mathrm{mL}^{-1}$ and $34.2 \mathrm{pg} \cdot \mathrm{mL}^{-1}$, respectively, whereas pre-treatment with $100 \mu \mathrm{M} \mathrm{CM}$ had no effect (fig. 6a). Similar results were observed for IL-6, in that the mean concentration of IL- 6 was $401 \mathrm{pg} \cdot \mathrm{mL}^{-1}$ in the control group and $650 \mathrm{pg} \cdot \mathrm{mL}^{-1}$ in the RV group. In cells pre-treated 


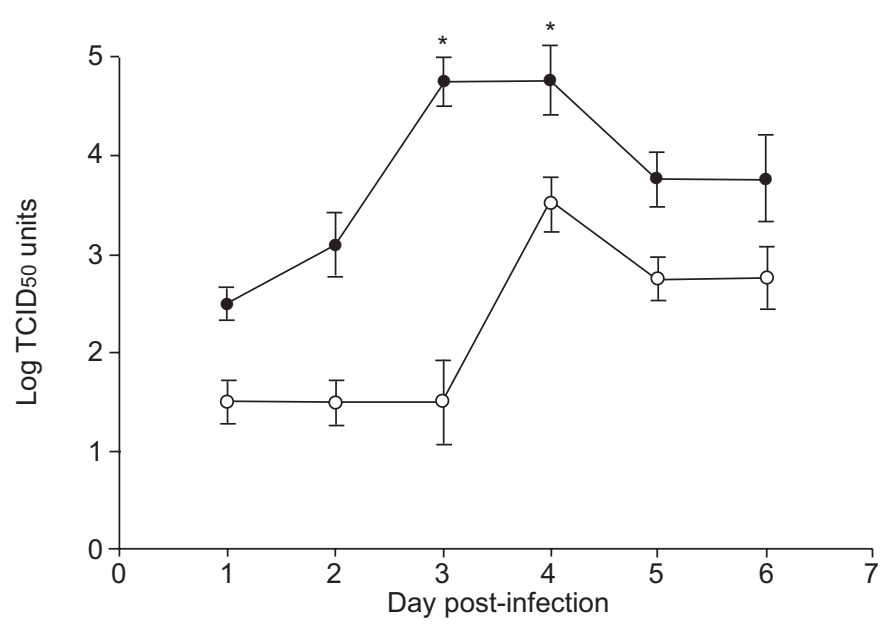

FIGURE 3. Effect of clarithromycin (CM) pre-treatment on the time course of viral titres in supernatants of rhinovirus (RV)-infected A549 cells. Each point represents the mean $\pm S D$ of seven samples. $\bullet: R V$; O: RV+CM. TCID50: $50 \%$ tissue culture infection dose. ${ }^{*}: p<0.05$.

with 1,10 and $100 \mu \mathrm{M} \mathrm{CM}$ and then infected with RV, the mean concentration of IL- 6 was 479,435 and $474 \mathrm{pg} \cdot \mathrm{mL}^{-1}$, respectively (fig. 6b). The mean concentration of IL-8 was $1,383 \mathrm{pg} \cdot \mathrm{mL}^{-1}$ in the control group and $2,028 \mathrm{pg} \cdot \mathrm{mL}^{-1}$ in the $\mathrm{RV}$ group, whereas in cells pre-treated with 1,10 and $100 \mu \mathrm{M}$ $\mathrm{CM}$ prior to infection, the mean concentration of IL-8 was $1,491,1,189$ and $1,528 \mathrm{pg} \cdot \mathrm{mL}^{-1}$, respectively (fig. 6c). The maximum inhibitory effect of $\mathrm{CM}$ on RV-induced increase in IL-8 secretion was seen at $10 \mu \mathrm{M}$ concentration (fig. 6c).

The time course of cytokine secretion was also measured. In infected cells, the concentration of IL- $1 \beta$ reached a maximum of $62.5 \mathrm{pg} \cdot \mathrm{mL}^{-1}$ on day 3 , and then gradually declined to $51.9 \mathrm{pg} \cdot \mathrm{mL}^{-1}$ on day 6 . In cells pre-treated with $\mathrm{CM}$ for 3 days prior to viral infection, the IL-1 $\beta$ concentration showed a similar pattern, but with significantly lower concentrations $(\mathrm{p}<0.05$; fig. 7a). In infected cells, the concentrations of secreted IL-6 increased from $424 \mathrm{pg} \cdot \mathrm{mL}^{-1}$ on day 1 to $727 \mathrm{pg} \cdot \mathrm{mL}^{-1}$ on day 6 . However, in cells pre-treated with $\mathrm{CM}$ the IL-6 level declined slightly until day 3 and then increased from day 4 to day 6 (fig. $7 \mathrm{~b}$ ). In infected cells, the concentrations of secreted IL-8 increased from $1,443 \mathrm{pg} \cdot \mathrm{mL}^{-1}$

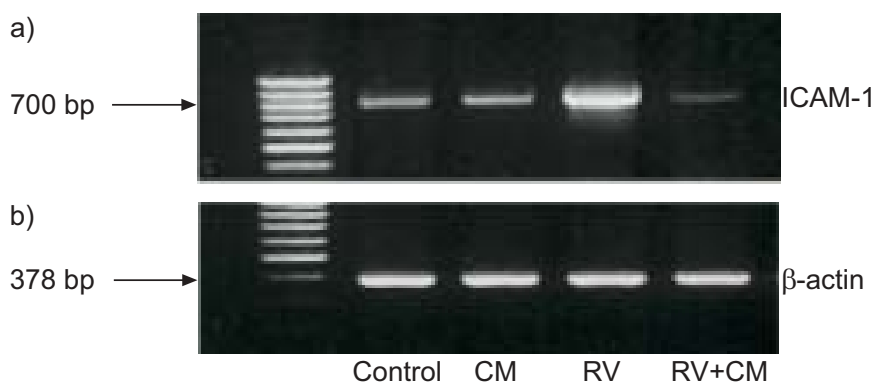

FIGURE 4. RT-PCR showing expression of a) intercellular adhesion molecule (ICAM)-1 mRNA and b) $\beta$-actin mRNA. Cells were uninfected and untreated (control), treated with clarithromycin (CM) alone, infected with rhinovirus (RV), or treated with $\mathrm{CM}$ from 3 days prior to $\mathrm{RV}$ infection $(\mathrm{RV}+\mathrm{CM})$. bp: base pairs. on day 1 to $2,807 \mathrm{pg} \cdot \mathrm{mL}^{-1}$ on day 6 , while in cells pre-treated with $\mathrm{CM}$, the concentration of secreted IL- 8 level increased from $1,264 \mathrm{pg} \cdot \mathrm{mL}^{-1}$ on day 1 to $2,298 \mathrm{pg} \cdot \mathrm{mL}^{-1}$ on day 6 (fig. $7 \mathrm{c}$ ).

The cytokine secretion in cells pre-treated with $\mathrm{CM}$ before infection with cells to which $\mathrm{CM}$ was added at the time of infection was also compared. Secretion of IL-1 $\beta$ (fig. 8a) and IL6 (fig. 8b), both of which were increased by RV infection, was inhibited by $\mathrm{CM}$ treatment both before and at the time of infection $(p<0.05)$. In contrast, the ability of CM to inhibit IL-8 secretion was significant only when cells were pre-treated with $\mathrm{CM}$, and not when it was added at the time of viral infection (fig. 8c).

\section{DISCUSSION}

Recent studies have demonstrated that, in addition to its antibacterial effects, the long-term, low-dose usage of macrolide antibiotics has anti-inflammatory activity in the management of chronic airway disease. CM, for example, has been found to suppress the production of IL- $1 \beta$, IL-6, IL-8, and granulocyte-macrophage colony stimulating factor [18-21], as well as to reduce ICAM-1 gene expression on nasal fibroblasts [18]. As ICAM-1 is the receptor for the major RVs, and since IL$1 \beta$, IL-6, and IL-8 play significant roles in the pathophysiology of RV infection [22], CM may be able to modulate inflammatory processes during RV infection. To evaluate its potential role in modulating RV-related inflammation, the effects of CM on RV-induced changes in viral titre, ICAM-1 expression and cytokine production in A549 respiratory epithelial cells were assayed.

It was found that $\mathrm{CM}$ reduced RV titres in the supernatants of infected A549 cells, with the degree of reduction being greater in cells pre-treated with $\mathrm{CM}$ than in cells administered with $\mathrm{CM}$ at the time of the infection. Interestingly, it was found that 1 and $10 \mu \mathrm{M} \mathrm{CM}$ were more effective than $100 \mu \mathrm{M} \mathrm{CM}$,

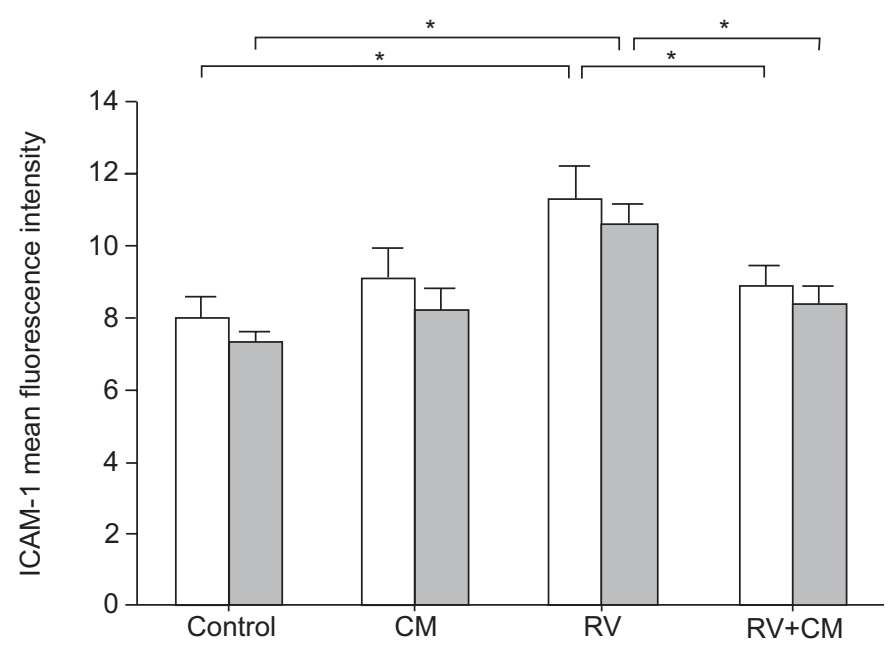

FIGURE 5. Effects of clarithromycin (CM) on intercellular adhesion molecule (ICAM)-1 fluorescence intensity in A549 cells after rhinovirus (RV) infection. Regardless of pre-treatment, $\mathrm{CM}$ treatment of infected cells $(\mathrm{RV}+\mathrm{CM})$ inhibited the RV-induced increased expression of ICAM-1 (RV). However, CM had no effect on the constitutive expression of ICAM-1 in A549 cells (control). Each bar represents the mean \pm SD of seven samples. $\square$ : pre-treatment; $\square$ : no pre-treatment. $*: p<0.05$. 

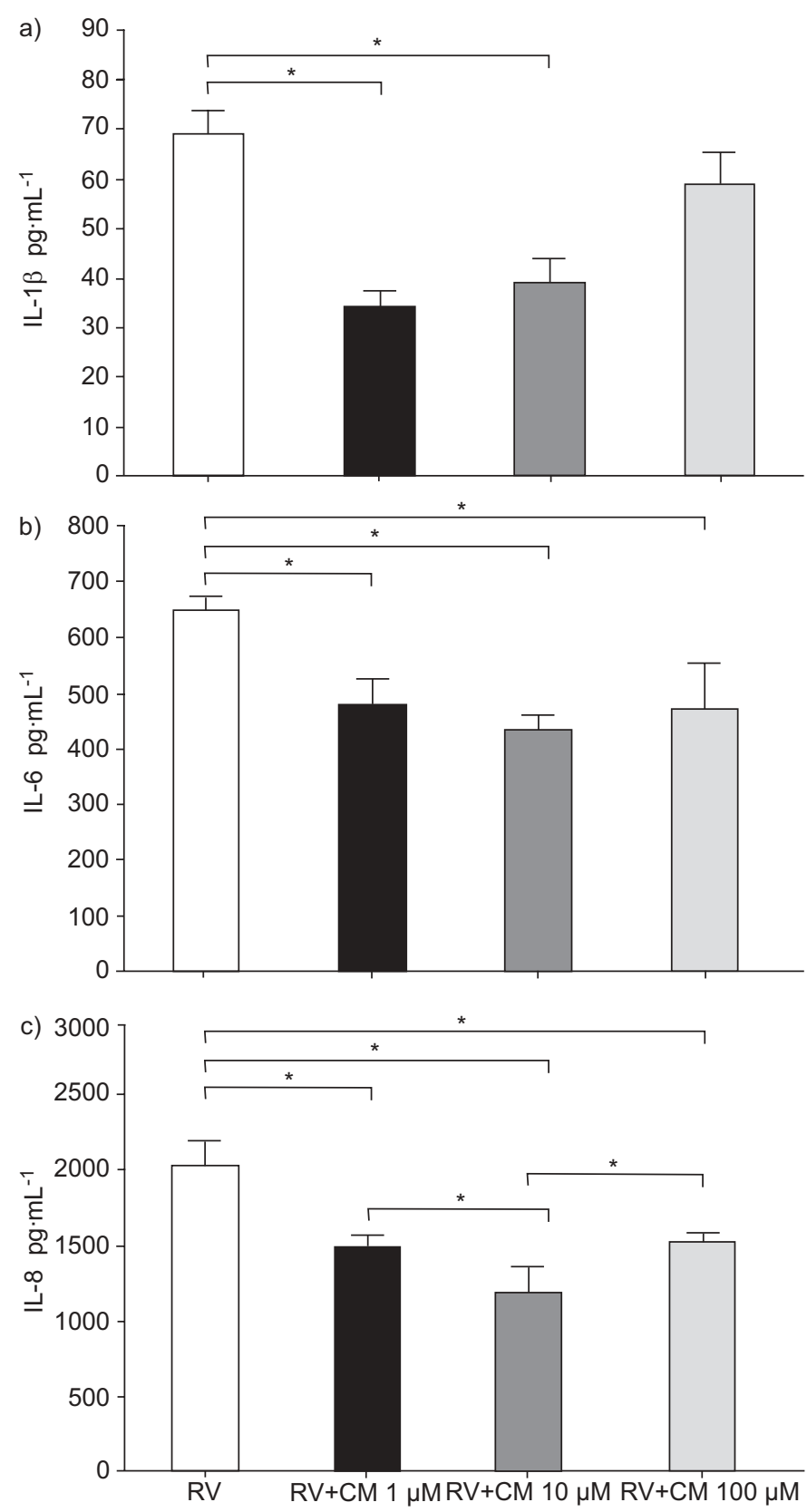

FIGURE 6. Effects of different concentrations of clarithromycin (CM) pretreatment on the secretion of a) interleukin (IL)-1 $\beta$, b) IL-6 and c) IL-8 by rhinovirus (RV)-infected A549 cells. Each bar represents the mean \pm SD of seven samples. *: $p<0.05$.

particularly on day 3 after infection. The average serum concentration of $\mathrm{CM}$, in clinical use has been reported to be $10 \mu \mathrm{M}$ [23]. Thus, the result of this study supports evidence for the effectiveness of low-dose CM in clinical practice. In the absence of CM, the viral titre peaked on days 3 and 4 after infection and then declined. The optimal effect of $\mathrm{CM}$ in reducing the RV-induced increase was seen on day 3 after infection, suggesting that the optimal time point for determining the effect of CM on RV infection would be at day 3. It has been suggested that erythromycin inhibits RV infection by reducing ICAM-1 and by blocking the RV RNA entry into the
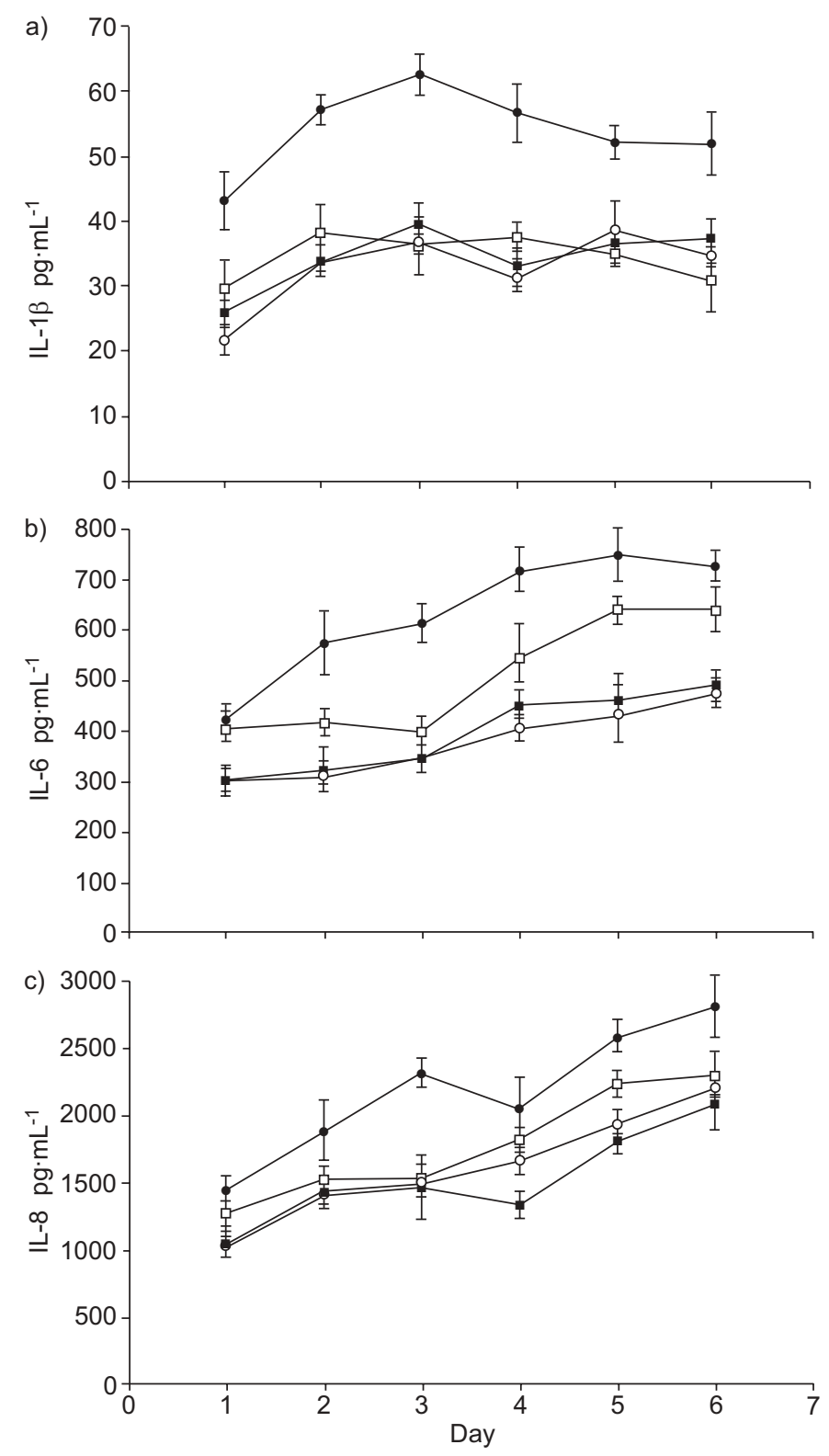

FIGURE 7. Effects of clarithromycin (CM) pre-treatment on the time course of secretion of a) interleukin (IL)-1 $\beta$, b) IL-6 and c) IL-8 by rhinovirus (RV)-infected A549 cells. Cells were uninfected and untreated (control; $\bigcirc$ ), treated with $\mathrm{CM}$ alone ( $\mathbf{\square})$, infected with RV $(\bullet)$, or treated with CM from 3 days prior to RV infection ( $\square$ ). Each bar represents the mean \pm SD of seven samples.

endosomes [17]. The decrease in viral titre following $\mathrm{CM}$ treatment in the current study may also have been caused by similar mechanisms suggested by SUZUKI et al. [17].

ICAM-1 is a glycoprotein expressed on the cell surface of vascular endothelial cells, epithelial cells, and fibroblasts, and has been shown to be involved in leukocyte trafficking and recruitment to the sites of inflammation. In addition, ICAM-1 expression on respiratory epithelium is increased by RV infection $[5,22]$. It was found that ICAM-1 mRNA and protein were constitutively expressed by A549 cells and that their levels were significantly increased by RV-16 infection, a finding in agreement with previous observation $[5,6]$. 

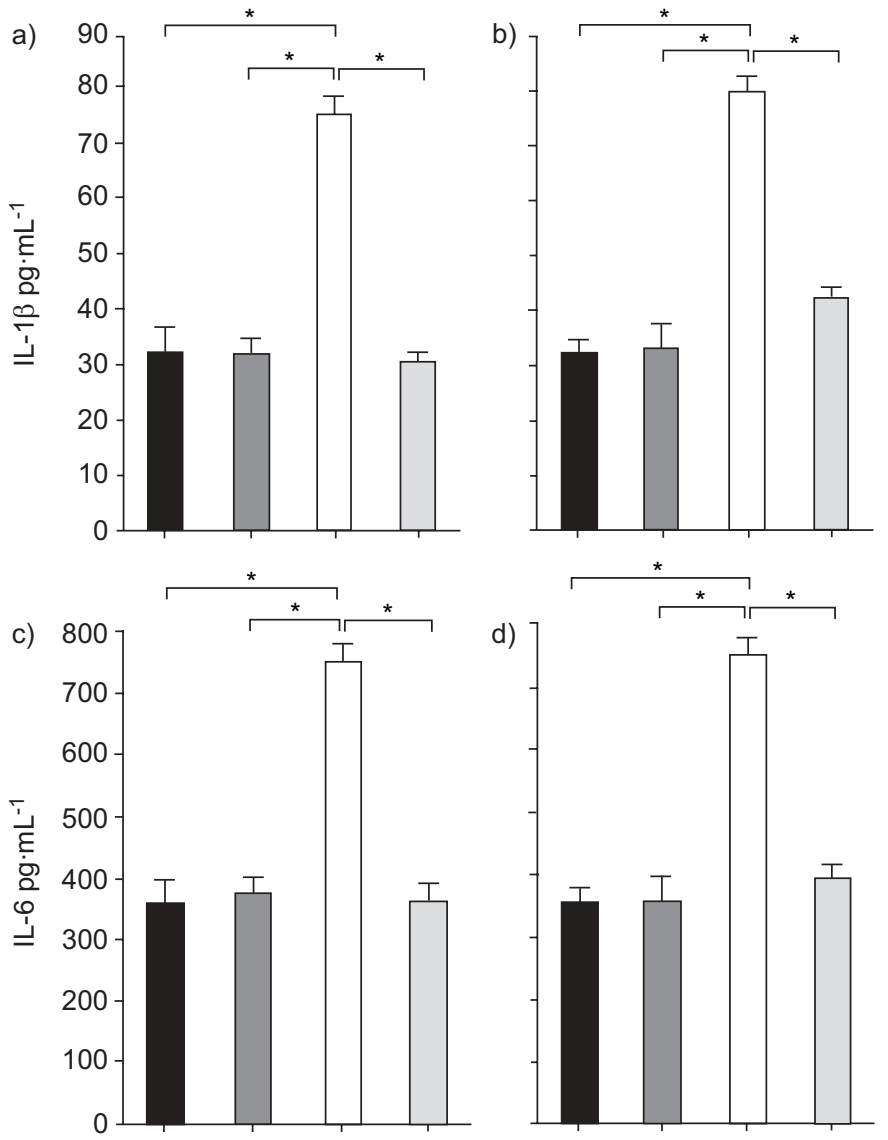

d)
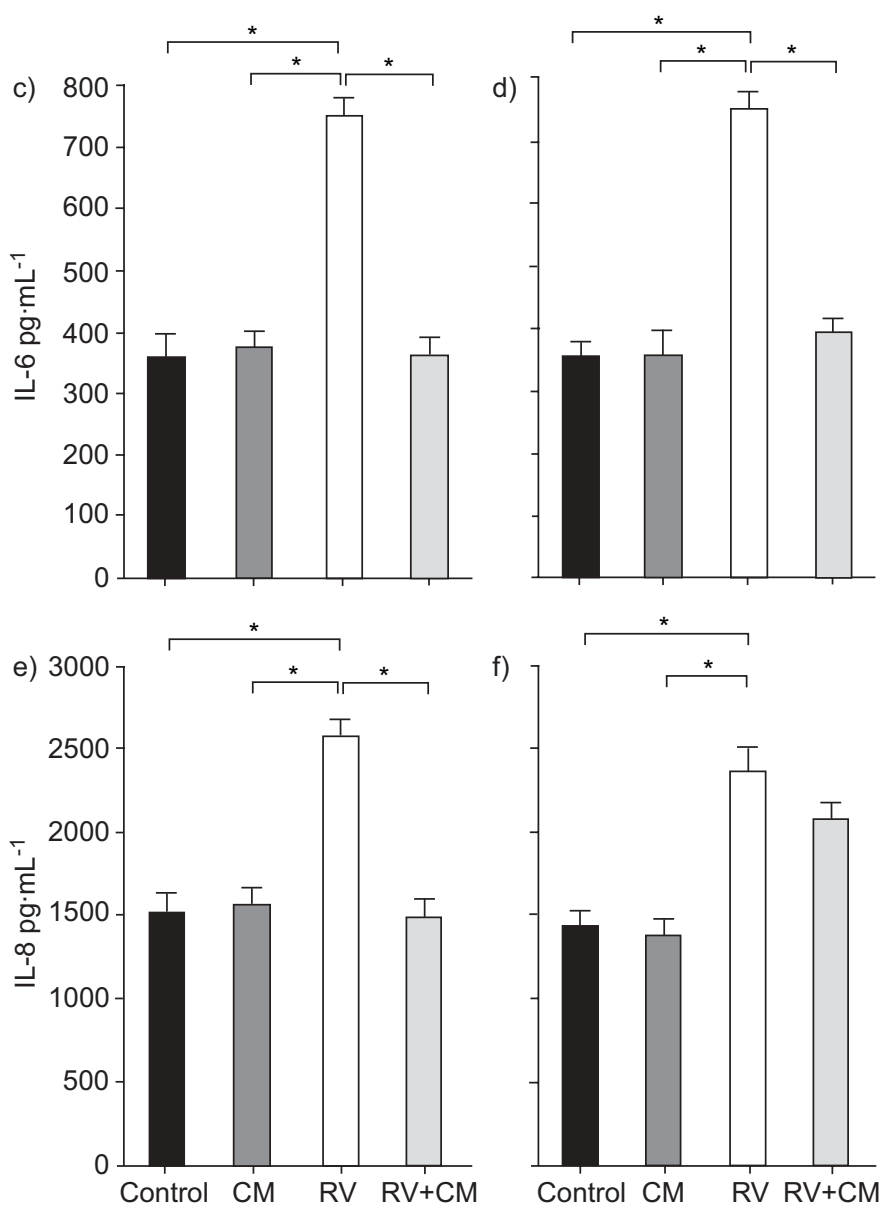

FIGURE 8. Effects of clarithromycin (CM) treatment on the secretion of a) interleukin (IL)-1 $\beta$, b) IL-6 and c) IL-8 by rhinovirus (RV)-infected A549 cells. a), c), and e) Cells were pre-treated with $\mathrm{CM}$ from 3 days prior to infection. b), d) and f) $\mathrm{CM}$ was added at the time of infection. Cells were uninfected and untreated (control), treated with clarithromycin (CM) alone, infected with rhinovirus (RV), or infected with $\mathrm{RV}$ and treated with $\mathrm{CM}(\mathrm{RV}+\mathrm{CM})$. Each bar represents the mean $\pm \mathrm{SD}$ of seven samples. *: $p<0.05$.

Although, in the absence of infection, treatment with CM did not alter baseline mRNA expression or ICAM-1-specific fluorescence intensity, CM reduced the RV-induced increases in ICAM-1 mRNA and specific fluorescence intensity, regardless of whether the $\mathrm{CM}$ was added 3 days before or at the time of RV infection.
It was also found that RV infection increased IL-1 $\beta$ production by $\mathrm{A} 549$ cells and that this increase was inhibited by CM. IL-1 $\beta$ is important in the inflammatory process involved in RV infection, as it increases vascular permeability and induces IL-8 release from epithelial cells. IL-1 $\beta$ also upregulates ICAM-1 mRNA and increases ICAM-1 expression in both epithelial and vascular endothelial cells, thereby increasing cell susceptibility to RV infection $[6,22]$. The current finding that CM inhibited the RV-induced increase in IL-1 $\beta$ suggests that CM may have a significant impact on RV infection by further inhibiting the IL-1 $\beta$ upregulation of ICAM- 1 and IL-8. In addition, it was observed that CM inhibited the RV-induced increase in IL-6 and IL- 8 secretion, while having no effect on the constitutive production of these cytokines. IL-6 can also participate in common cold symptoms, since it induces pyrexia [22]. IL-8 is of great importance in RV-induced colds, as it is a strong chemoattractant for neutrophils; it can also activate the recruited neutrophils, resulting in the release of their cytotoxic granule content $[8,22]$. RVs are potent stimulators of IL-6 and IL-8 production, and there is substantial evidence for a direct correlation between the level of IL- 6 and IL- 8 and symptom severity in experimental RV colds [24]. The observation that CM has inhibitory effects on the RV-induced increases in IL-6 and IL- 8 secretion suggests that CM may relieve the symptoms of RV infection.

When the effects of CM pre-treatment on RV-induced cytokine secretion were assayed, it was found that administration of $\mathrm{CM}$ at the time of infection inhibited secretion of IL-1 $\beta$ and IL-6, but not IL-8, whereas all three were inhibited by CM pretreatment, suggesting that $\mathrm{CM}$ may be more effective in inhibiting IL-8 secretion when used prophylactically. However, the reasons why the secretions of IL-1 $\beta$ and IL-6 were not affected by the different modes of treatment need to be clarified by future studies.

In contrast to the findings in RV-infected cells, it was found that $\mathrm{CM}$ did not inhibit the constitutive expression of ICAM-1, IL-1 $\beta$, IL-6, and IL-8. This result is not in agreement with a previous investigation in which macrolide antibiotics and other drugs were reported to inhibit the constitutive expression of ICAM-1 and cytokines [17, 25, 26]. However, CM pretreatment was found to suppress IL-1 $\beta$ induced nuclear factor (NF)- $\kappa \mathrm{B}$ activity in bronchial epithelial cells, but had no effect on NF- $\kappa B$ activity in the absence of IL- $1 \beta$ stimulation [13]. Since the ability of macrolides to inhibit the secretion of pro-inflammatory cytokine is mediated by inhibition of NF- $\kappa \mathrm{B}$ [27], CM may have no effect on the constitutive expression of ICAM-1 and pro-inflammatory cytokines, which may not be associated with NF- $\kappa B$ activation [18]. However, further experiments are required to clarify this discrepancy.

Another 14-membered-ring macrolide antibiotic, erythromycin, has been reported to inhibit RV-14 infection by reducing ICAM-1 expression and to modulate airway inflammation by reducing the production of pro-inflammatory cytokines [17]. In addition, treatment of cells with erythromycin significantly decreased RV titre, thus providing evidence of the potentially beneficial role of macrolide antibiotics in RV infection. 
However, in a double-blinded clinical trial CM treatment had little or no effect on the severity of cold symptoms or the intensity of neutrophilic nasal inflammation [28]. Similarly, $\mathrm{CM}$ was found to reduce cellular expression of tumour growth factor- $\beta$ and NF- $\kappa B$ in vitro, but not in mucosal specimens in vivo. [19] The discrepancy between the results of this study and those of the in vivo clinical trial [28] may be due to differences in dosage or mode of treatment. For example, in the clinical trial, $1,000 \mathrm{mg} \cdot$ day $^{-1}$ of $\mathrm{CM}$, a higher dose than the $250 \mathrm{mg} \cdot$ day $^{-1}$ usually used for low-dose, long-term treatment [29], was started $24 \mathrm{~h}$ before inoculation of RV. However, it was found that CM started 3 days before RV infection was more effective than $\mathrm{CM}$ started at the time of infection, and that $10 \mu \mathrm{M} \mathrm{CM}$, the usual blood level in clinical use, was more effective than $100 \mu \mathrm{M}$ in reducing viral titre and cytokine secretion. In another report [30], the longer CM pre-treatment times have been found to be more effective at inhibiting the induced cytokine secretion. Thus, additional clinical trials using lower doses of $\mathrm{CM}$ with longer pre-treatment duration may result in different outcomes than those described [28].

In conclusion, although clarithromycin has been clinically used for the treatment of patients with bacterial infections, the results of this study suggest that this antibiotic may have a possible clinical application in the prevention of rhinovirus infection and in the treatment of airway inflammation caused by rhinovirus infection.

\section{REFERENCES}

1 Gwaltney JM Jr, Hendley JO, Simon G, Jordan WS Jr. Rhinovirus infections in an industrial population. I. The occurrence of illness. N Engl J Med 1966; 275: 1261-1268.

2 Greenberg SB. Respiratory consequences of rhinovirus infection. Arch Intern Med 2003; 163: 278-284.

3 Casasnovas JM, Springer TA. Pathway of rhinovirus disruption by soluble intercellular adhesion molecule 1 (ICAM-1): an intermediate in which ICAM-1 is bound and RNA is released. J Virol 1994; 68: 5882-5889.

4 Greve JM, Davis G, Meyer AM, et al. The major human rhinovirus receptor is ICAM-1. Cell 1989; 56: 839-847.

5 Papi A, Papadopoulos NG, Stanciu LA, et al. Reducing agents inhibit rhinovirus-induced up-regulation of the rhinovirus receptor intercellular adhesion molecule-1 (ICAM-1) in respiratory epithelial cells. FASEB J 2002; 16: 1934-1936.

6 Terajima M, Yamaya M, Sekizawa K, et al. Rhinovirus infection of primary cultures of human tracheal epithelium: role of ICAM-1 and IL-1 $\beta$. Am J Physiol 1997; 273: L749-L759.

7 Yuta A, Doyle WJ, Gaumond E, et al. Rhinovirus infection induces mucus hypersecretion. Am J Physiol 1998; 274: L1017-L1023.

8 Zhu Z, Tang W, Gwaltney JM Jr, Wu Y, Elias JA. Rhinovirus stimulation of interleukin-8 in vivo and in vitro: role of NF-kB. Am J Physiol 1997; 273: L814-L824.

9 Grunstein MM, Hakonarson H, Maskeri N, Chuang S. Autocrine cytokine signaling mediates effects of rhinovirus on airway responsiveness. Am J Physiol Lung Cell Mol Physiol 2000; 278: L1146-L1153.
10 Kadota J, Sakito O, Kohno S, et al. A mechanism of erythromycin treatment in patients with diffuse panbronchiolitis. Am Rev Respir Dis 1993; 147: 153-159.

11 Nagai H, Shishido M, Yoneda R, Yamaguchi E, Tamura A, Kurashima A. Long-term low dose administration of erythromycin to patients with diffuse panbronchiolitis. Respiration 1991; 58: 145-149.

12 Hashiba M, Baba S. Efficacy of long-term administration of clarithromycin in the treatment of intractable chronic sinusitis. Acta Otolaryngol 1996; 525: Suppl., 73-78.

13 Khair OA, Devalia JL, Abdelazia MM, Sapsford RJ, Davies RJ. Effect of erythromycin on Haemophilus influenzae endotoxin-induced release of IL-6, IL- 8 and sICAM- 1 by cultured human bronchial epithelial cells. Eur Respir J 1995; 8: 1451-1457.

14 Takizawa H, Desaki M, Ohtoshi T, et al. Erythromycin suppresses interleukin 6 expression by human bronchial epithelial cells: a potential mechanism of its antiinflammatory action. Biochem Biophys Res Commun 1995; 210: 781-786.

15 Takizawa H, Desaki M, Ohtoshi T, et al. Erythromycin modulates IL-8 expression in normal, and inflamed human bronchial epithelial cells. Am J Respir Crit Care Med 1997; 156: 266-271.

16 Tamaoki J, Sakai N, Tagaya E, Konno K. Macrolide antibiotics protect against endotoxin-induced vascular leakage and neutrophil accumulation in rat trachea. Antimicrob Agents Chemother 1994; 38: 1641-1643.

17 Suzuki T, Yamaya M, Sekizawa K, et al. Erythromycin inhibits rhinovirus infection in cultured human tracheal epithelial cells. Am J Respir Crit Care Med 2002; 165: 1113-1118.

18 Miyanohara T, Ushikai M, Matsune S, Ueno K, Katahira S, Kurono Y. Effects of clarithromycin on cultured human nasal epithelial cells and fibroblasts. Laryngoscope 2000; 110: 126-131.

19 Wallwork B, Coman W, Mackay-Sim A, Cervin A. Effect of clarithromycin on nuclear factor- kappa B and transforming growth factor-beta in chronic rhinosinusitis. Laryngoscope 2004; 114: 286-290.

20 Matsuoka N, Eguchi K, Kawakami A, et al. Inhibitory effect of clarithromycin on costimulatory molecule expression and cytokine production by synovial fibroblast-like cell. Clin Exp Immunol 1996; 104: 501-508.

21 Fujita K, Shimizu T, Majima Y, Sakakura Y. Effects of macrolides on interleukin-8 secretion from human nasal epithelial cells. Eur Arch Otorhinolaryngol 2000; 257: 199-204.

22 van Kempen $M$, Bachert $C$, van Cauwenberge P. An update on the pathophysiology of upper respiratory tract infections. Rhinology 1999; 37: 97-103.

23 Suwa T, Urano H, Watanabe H. Pharmacokinetic study of TE-031(8). Absorption and excretion following oral administration of healthy volunteers. Chemotherapy (Tokyo) 1988; 36: 75-85.

24 Gern JE, Busse WW. Association of rhinovirus infections with asthma. Clin Microbiol Rev 1999; 12: 9-18.

25 Suzuki H, Shimomura A, Ikeda K, Furukawa M, Oshima T, Takasaka T. Inhibitory effect of macrolides on interleukin- 8 secretion from cultured human nasal epithlelial cells. Laryngoscope 1997; 107: 1661-1666. 
26 Sasaki T, Yamaya M, Yasuda H, et al. The proton pump inhibitor lansoprazole inhibits rhinovirus infection in cultured human tracheal epithelial cells. Eur J Phamarcol 2005; 509: 201-210.

27 Ichiyama T, Nishikawa M, Yoshitomi $\mathrm{T}$, et al. Clarithromycin inhibits NF-kB activation in human peripheral blood mononuclear cells and pulmonary epithelial cells. Antimicrob Agents Chemother 2001; 45: 44-47.

28 Abisheganaden JA, Avila PC, Kishiyama JL, et al. Effect of clarithromycin on experimental rhinovirus-16 colds: a randomized, double blind, controlled trial. Am J Med 2000; 108: 453-459.

29 Cervin A, Kalm O, Sandkull P, Lindberg S. One-year low-dose erythromycin treatment of persistent chronic sinusitis after sinus surgery: clinical outcome and effects on mucociliary parameters and nasal nitric oxide. Otolaryngol Head Neck Surg 2002; 126: 481-489.

30 Terao H, Asano K, Kanai K, et al. Suppressive activity of macrolide antibiotics on nitric oxide production by lipopolysaccharide stimulation in mice. Mediators Inflamm 2003; 12: 195-202. 